\title{
Novel methods of synthesis for diesel fuel OME
}

Dr. Eberhard Jacob, Co-Author: Wolfgang Maus, both Continental Emitec $\mathrm{GmbH}$

Zum Zeitpunkt der Drucklegung lagen diese Unterlagen noch nicht vor. Wir bitten um Verständnis. 